\title{
ISL-1 is overexpressed in non-Hodgkin lymphoma and promotes lymphoma cell proliferation by forming a p-STAT3/p-c-Jun/ISL-1 complex
}

Qiao Zhang ${ }^{1+}$, Zhe Yang ${ }^{1 \dagger}$, Zhuqing Jia', Cuiling Liu², Chen Guo ${ }^{1}$, Huafei Lu', Ping Chen ${ }^{1}$, Kangtao Ma', Weiping Wang ${ }^{1 *}$ and Chunyan Zhou ${ }^{1 *}$

\begin{abstract}
Background: Insulin enhancer binding protein-1 (ISL-1), a LIM-homeodomain transcription factor, is essential for the heart, motor neuron and pancreas development. Recently, ISL-1 has been found in some types of human cancers. However, how ISL-1 exerts the role in tumor development is not clear.

Methods and results: The expression of ISL-1 was assessed in 211 human lymphoma samples and 23 normal lymph node samples. Immunohistochemistry results demonstrated a markedly higher expression of ISL-1 in 75\% of non-Hodgkin lymphoma (NHL) samples compared with that in normal lymph nodes or Hodgkin lymphoma (HL) samples. CCK-8 analysis, cell cycle assay and xenograft model were performed to characterize the association between ISL-1 expression level and biological functions in NHL. The results showed that ISL-1 overexpression obviously promoted NHL cells proliferation, changed the cell cycle distribution in vitro and significantly enhanced xenografted lymphoma development in vivo. Real-time PCR, Western blot, luciferase assay and ChIP assay were used to explore the potential regulatory targets of ISL-1 and the results demonstrated that ISL-1 activated the c-Myc expression in NHL by direct binding to a conserved binding site on the c-Myc enhancer. Further results revealed that ISL-1 could be positively regulated by the c-Jun N-terminal kinase (JNK) and the Janus kinase/signal transducer and activator of transcription (JAK/STAT) pathways. Both the JNK and JAK/STAT signaling inhibitors could significantly suppressed the growth of NHL cells through the down-regulation of ISL-1 as demonstrated by CCK-8 and Western blot assays. Bioinformatic analysis and luciferase assay exhibited that ISL-1 was a novel target of p-STAT3 and p-c-jun. ChIP, Co-IP and ChIP-re-IP analysis revealed that ISL-1 could participate with p-STAT3 and p-c-Jun to form a p-STAT3/p-c-Jun/ISL-1 transcriptional complex that binds directly on the ISL-1 promoter, demonstrating a positive feedback regulatory mechanism for ISL-1 expression in NHL.
\end{abstract}

Conclusions: Our results provide the first evidence that ISL-1 is tightly linked to NHL proliferation and development by promoting c-Myc transcription, and its aberrant expression was regulated by p-STAT3/p-c-Jun/ISL-1 complex activation.

Keywords: ISL-1, Lymphomagenesis, Signal transduction, Transcriptional complex

\footnotetext{
* Correspondence: wwp@bjmu.edu.cn; chunyanzhou@bjmu.edu.cn

${ }^{\dagger}$ Equal contributors

'Department of Biochemistry and Molecular Biology, School of Basic Medical

Sciences, Key Laboratory of Molecular Cardiovascular Sciences, Ministry of

Education of China, Peking University, 38 Xueyuan Road, 100191 Beijing,

China

Full list of author information is available at the end of the article
}

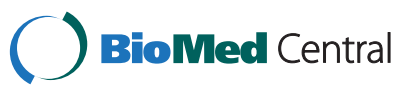

(c) 2014 Zhang et al.; licensee BioMed Central Ltd. This is an Open Access article distributed under the terms of the Creative Commons Attribution License (http://creativecommons.org/licenses/by/4.0), which permits unrestricted use, distribution, and reproduction in any medium, provided the original work is properly credited. The Creative Commons Public Domain Dedication waiver (http://creativecommons.org/publicdomain/zero/1.0/) applies to the data made available in this article, unless otherwise stated. 


\section{Introduction}

Malignant lymphoma is a group of hematological malignancies, which includes Hodgkin lymphoma (HL) and non-Hodgkin lymphoma (NHL). NHL make up around $90 \%$, and $\mathrm{HL}$ account for the remaining $10 \%$ of all malignant lymphomas [1]. NHL is generally classified according to its origin, that is, B-cell NHL and T/NK-cell NHL. The most common NHL subtypes by far in developed countries are diffuse large B-cell lymphoma (DLBCL) and follicular lymphoma (FL). All other NHL subtypes have a frequency of less than 10\% [1]. NHL is the seventh most frequent cancer and the incidence rate has increased markedly in recent years [2]. Although some progress is being made, the fundamental abnormalities underlying NHL still remain unclear. The molecular mechanisms responsible for the etiology of NHL are poorly understood and their elucidation could improve current therapeutic approaches.

Insulin enhancer binding protein-1 (ISL-1) is a member of LIM-homeodomain family. It is previously described to play crucial roles in the development of heart, motor neuron and pancreas [3-6]. Recent studies demonstrate that ISL-1 is also involved in postnatal physiology and pathology [7-9]. More reports indicate that ISL-1 may be closely related to the occurrence of a variety of tumors. High expression level of ISL-1 is detected in a majority of pancreatic endocrine tumors [10], all four subtypes of lung cancer [11], breast cancer [12], and nearly $65 \%$ of cholangiocarcinoma [13]. Most recent study indicates that ISL-1 is a sensitive but not entirely specific marker of pancreatic neuroendocrine neoplasms (NENs) and their metastases. The overall sensitivity and specificity of ISL-1 in identifying primary pancreatic NENs is $88 \%$ and $80 \%$, respectively [14]. Increasing evidences indicate an important role of ISL-1 in the development of some cancers. However, whether ISL-1 has any functional effect on tumorigenesis and how ISL-1 is regulated during cancer development are yet not clear.

In the present study, we investigate whether ISL-1 plays an oncogenic role in human tumors. We show that abnormal high expression of ISL-1 is significantly correlated with NHL and is specifically exhibited in $75 \%$ of human NHL samples we examined. Aberrant ISL-1 is regulated by $\mathrm{p}-\mathrm{STAT} 3 / \mathrm{p}-\mathrm{c}-J u n / \mathrm{ISL}-1$ transcription complex and potentiates NHL cells proliferation through up-regulating c-Myc expression. Our findings reveal the feasibility of ISL-1 as a potential therapeutic target for NHL treatment.

\section{Results}

ISL-1 is highly expressed in $75 \%$ of human NHL samples In our pilot study, the specimens from different types of tumors (colon, lung, breast, liver and ovarian neoplasms) were analyzed by immunohistochemical staining. The results showed a high expression level of ISL-1 in diffuse large B cell lymphoma (DLBCL, the most common lymphoma subtype and accounting for $30 \sim 40 \%$ of adult non-Hodgkin lymphoma [15]), compared with reactive lymph nodes (data not shown).

To examine the pathological relevance of ISL-1 in human lymphoma development, we analyzed the expression level and cellular distribution of ISL-1 in collected specimens and tissue microarrays by immunohistochemical staining. These tissue specimens included 23 normal lymph nodes and 211 lymphoma samples. The lymphoma specimens could be classified into two types: 195 NHL (159 B-cell lymphoma, $36 \mathrm{~T}$-cell lymphoma) and 16 Hodgkin lymphoma (HL). As summarized in Table 1, ISL-1 expression level is markedly elevated in $75 \%$ of 195 NHL samples. Only 3 cases of normal lymph nodes exhibited moderate ISL-1 immunostaining, none of the 23 normal lymph nodes or $16 \mathrm{HL}$ showed any strong positive staining for ISL-1. Figure 1A shows representative immunohistochemistry images of ISL-1 staining in human normal lymph node, HL and NHL. ISL-1 staining was predominantly detected in the nuclear of a series of NHL lymphoma cells and, to a much lesser extent, in the normal lymph nodes and HL samples. Statistical analysis revealed that there was no significant difference in the expression of ISL-1 between normal lymph nodes and HL samples $(p=0.13)$, whereas, the positive staining of ISL-1 was significantly correlated with NHLs compared with that in normal lymph nodes $(p<0.001)$ (Figure 1B).

Meanwhile, we found a predominant expression of ISL-1 in a variety of NHL cell lines (Figure 1C,D). These data establish that ISL-1 expression is highly elevated in the majority of NHLs and might be tightly linked to lymphomagenesis.

\section{ISL-1 promotes proliferation of NHL cells in vitro and enhances xenografted lymphoma development in vivo}

We have previously shown that ISL-1 promoted the proliferation of adult pancreatic islets cells [6]. We wonder whether up-regulated ISL-1 in NHL plays a role in promoting NHL cells proliferation and tumorigenesis. Therefore, Raji, Jurkat and Ly3 were electroporated with pcDNA3.1ISL1, or pLL3.7-ISL1-siRNA plasmid to establish stable ISL-1 overexpressing or knockdown NHL cell lines. ISL-1 expression level in stably transfected NHL cell lines was measured by Western blot analysis and the degree of ISL-1 expression changes was analyzed by gray scanning using Bio-Rad Quantity One software on the images from 3 independent experiments. The results showed that the expression level of ISL-1 was ameliorated approximately 7 folds in ISL-1 overexpressed Raji cells (Additional file 1: Figure S1A) and around 2.7 folds in ISL-1 overexpressed Ly3 and Jurkat cells (Additional file 1: Figure S1B,C), while the level of ISL-1 was attenuated to less than $10 \%$ in ISL-1 knockdown Ly3 and Jurkat cells (Additional 
Table 1 Immunohistochemistry of ISL-1 expression in non-Hodgkin lymphoma

\begin{tabular}{|c|c|c|c|c|c|}
\hline \multirow{2}{*}{ Lymphoma subtype } & \multirow{2}{*}{ No. samples } & \multicolumn{3}{|c|}{ Staining } & \multirow{2}{*}{$\%$ positive $^{*}$} \\
\hline & & Negative & Weak & $\overline{\text { Strong }}$ & \\
\hline \multicolumn{6}{|l|}{ B-cell lymphoma $(n=159)$} \\
\hline DLBCL & 139 & 2 & 24 & 113 & 81 \\
\hline Follicular Lymphoma & 8 & 1 & 5 & 2 & 25 \\
\hline Mantle cell lymphoma & 4 & 0 & 1 & 3 & 75 \\
\hline Burkitt lymphoma & 3 & 0 & 1 & 2 & 67 \\
\hline Lymphoplasmacytic lymphoma & 5 & 0 & 1 & 4 & 80 \\
\hline T-cell lymphoma & 36 & 3 & 10 & 23 & 64 \\
\hline Total & 195 & 6 & 42 & 147 & 75 \\
\hline
\end{tabular}

*Positive percentage is determined by number of strong staining samples over the total number of samples.

file 1: Figure $\mathrm{S} 1 \mathrm{~B}, \mathrm{C})$, indicating that both overexpression and knockdown cell lines are successfully established. When ISL-1 protein level was up or down-regulated, notable promotion or inhibition of cell growth were observed in corresponding cell lines (Figure 2A). To further determine the role of ISL-1 on proliferation of NHL cells, the cell cycle profiles were analyzed. Compared with the control, Raji, Ly3 and Jurkat cells with ISL-1overexpression showed a decreased cell population in $G_{1}$ phase and a remarkably increased cell population in the $S$ and $G_{2} / M$ phases. Conversely, Ly3 and Jurkat cells with ISL-1 knockdown exhibited an increase in the proportion of cells in $G_{1}$ phase and a decrease in the proportion of cells in $S$ and $G_{2} / M$ phases (Figure $2 B$ ). These results indicate that ISL-1 could significantly change the cell cycle dynamics and thus promote NHL cells proliferation.

To further confirm whether ISL-1 could promote tumor growth in vivo, we used the SCID mice xenograft model

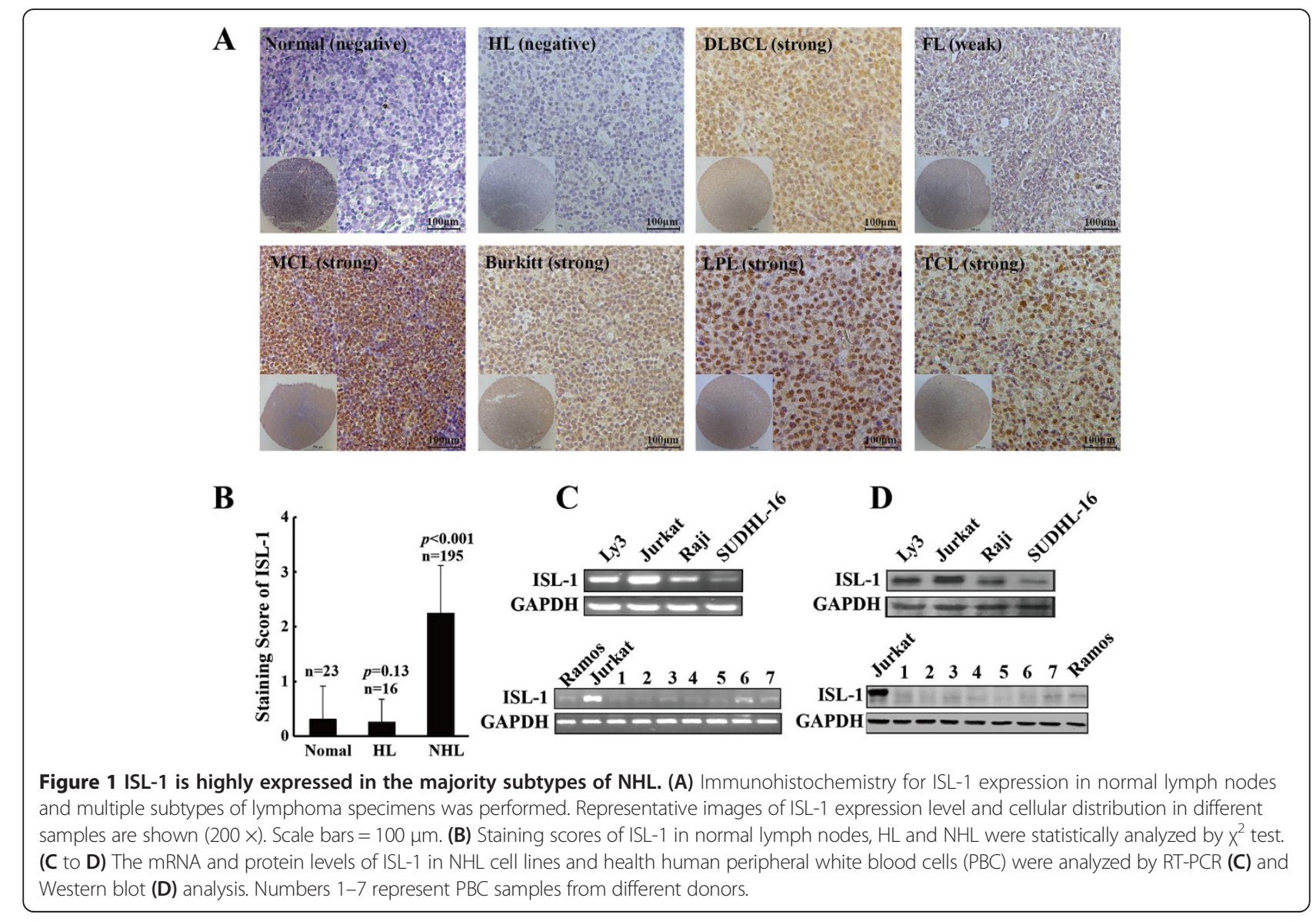



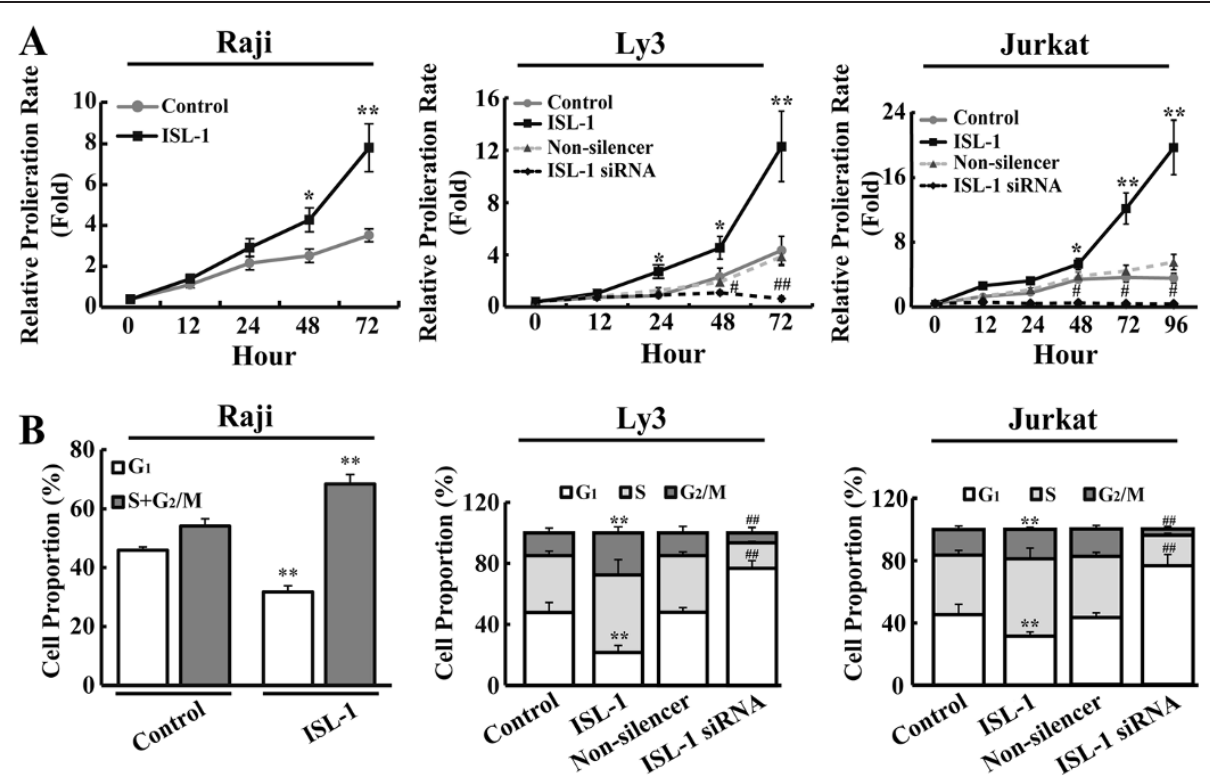

Figure 2 ISL-1 promotes NHL cells proliferation and affects cell-cycle phase distributions. (A) The relative proliferation rate of stably transfected cells was determined by CCK-8 assay at indicated time post-seeding. (B) Cell cycle distributions were analyzed by flow cytometry. The data represent three independent experiments. Each bar represents mean \pm SD. $p$ values were calculated using a Student $t$-test $\left(^{*} p<0.05,{ }^{* *} p<0.01,{ }^{\#} p<0.05\right.$, $\# p<0.01$ vs. each control). (Control, ISL-1, Non-silencer and ISL-1 siRNA represent the cells transfected with pcDNA3.1, pcDNA3.1-ISL-1, pLL3.7-Non-silencer or pLL3.7-ISL1-siRNA plasmid, respectively)

to study the impact of ISL-1 on NHL genesis and development. We found that the initiation and the growth of tumor were significantly earlier and faster with ISL-1 overexpressing cells than those with the control cells (Figure 3A,C). Conversely, the tumor growth was obviously impaired with ISL-1 knockdown cells (Figure 3B,D). After the last measurement, the tumors were isolated and weighed. The ISL-1-overexpressing cells produced significantly larger and heavier tumors than the control cells, in contrast, the ISL-1-knockdown cells produced smaller and lighter tumors compared with the control cells (Additional file 2: Figure S2). We further compared the expression of ISL-1 in the tumor tissues isolated from the mice. As shown in Figure 3E, the protein level of ISL-1 in the tumors was positively correlated with the tumor volumes in each group. Therefore, our animal experiments confirm that ISL-1 potentiates NHL growth in vivo.

Collectively, in vitro and in vivo results indicate that overexpression of ISL-1 promotes NHL cells proliferation and enhances lymphoma development, whereas knockdown of ISL-1 attenuates NHL cells proliferation and inhibits xenograft growth.

\section{ISL-1 stimulates NHL cell proliferation through the up-regulation of c-Myc expression}

To explore the mechanism of ISL-1-stimulated NHL cell proliferation, bioinformatic analysis was performed with professional MatInspector software and refFlat Database to identify the downstream target genes of ISL-1. Several putative genes, including CyclinD1, BCL-6 and c-Myc were identified for further investigation, as these genes contain conserved ISL-1 binding sequences (YTAATGR) on the upstream of the ATG translation start site [16-18]. More importantly, they are remarkably related to the pathogenesis of NHL as previously reported [16-18]. However, the expression of CyclinD1 and BCL- 6 did not show a predicted correlation with ISL-1 in NHL cells (data not shown). Therefore, we focused on c-Myc in the rest investigations.

Western blot results showed that the basal expression level of c-Myc was positively correlated with the expression level of ISL-1 in NHL cell lines (will be discussed later in Figure 4A). Moreover, further results indicated that the overexpression of ISL-1 increased the expression of c-Myc at both mRNA and protein levels in Raji cells (Figure 5A, $B$ left panel). Whereas, the significant decrease of c-Myc expression was associated with the knockdown of ISL-1 as compared with those in the control Ly3 cells (Figure 5A,B right panel). These results show that ISL-1 could act as a transcriptional activator of c-Myc.

Furthermore, we uncovered that c-Myc is a direct transcriptional target of ISL-1. Bioinformatic analysis revealed a conserved ISL-1 binding site (TAAT) at $-1856 \sim-1852$ bp upstream of the ATG translation start site on the c-Myc enhancer region (Figure $5 \mathrm{C}$ ). Luciferase assay with $c-M y c-$ 

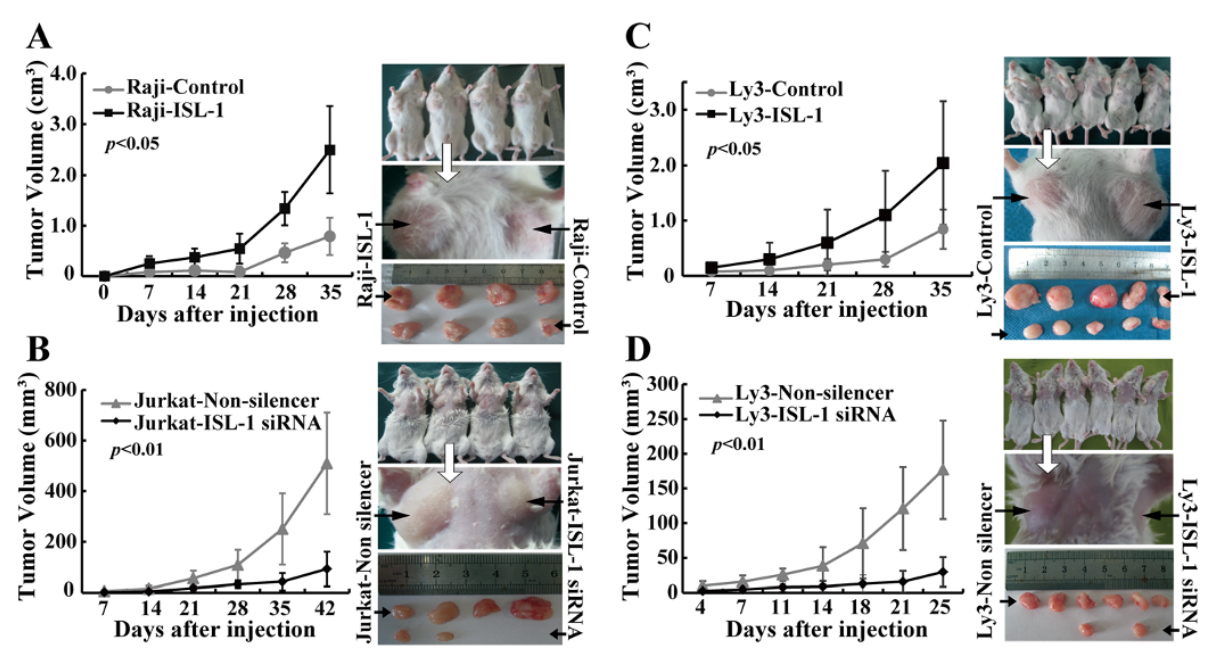

E

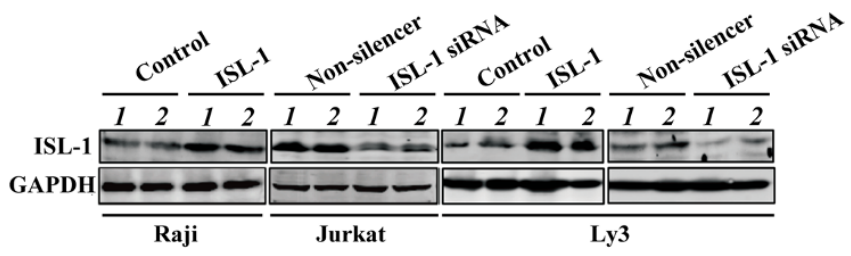

Figure 3 ISL-1 enhances xenografted lymphoma development in vivo. (A to D) NOD-SCID (nonobese diabetic/severe combined immunodeficient) mice were injected s.C. with different NHL cells that were stably transfected with pCDNA3.1 (Control), or pcDNA3.1-ISL-1 (ISL-1) construct (A,C), pLL3.7-Non-silencer or pLL3.7-ISL1-siRNA plasmid (B,D). The tumor size was monitored at indicated days post-injection. Statistical analysis was carried out with 2-way ANOVA. (E) The mice were killed after the last measurement of tumor volume, whole-cell lysate of 2 tumor samples of each group were prepared and subjected to Western blot analysis for ISL-1 level detection. GAPDH served as an internal control.

luc (a c-Myc luciferase reporter construct that contains the binding site for ISL-1 on the c-Myc enhancer) showed the stimulated $c$-Myc-luc activity in ISL-1-overexpressing cells in a dose-dependent manner, whereas a significant decrease of $c-M y c-l u c$ activity was seen in ISL-1-knockdown cells (Figure 5D). The constructs containing the mutant or deleted ISL-1 binding site on the c-Myc enhancer (Figure 5C), c-Myc-luc M1 ("TAAT" mutated to "cgAT"), c-Myc-luc M2 ("TAAT" mutated to "cggc"), c-Myc-luc D1 ("TAAT" with "TA" deleted) and c-Myc-luc D2 ("TAAT" completely deleted), exhibited a significant decrease of luciferase activity compared to the wild type $c$-Myc-luc (Figure 5E).

To determine if ISL-1 could occupy the c-Myc enhancer region in vivo, a specific primer covering the potential ISL-1 binding site located between -1935 and -1744 bp of c-Myc enhancer were designed (Figure 5C) and used for chromatin immunoprecipitation (ChIP) assay in Ly3 cells. As shown in Figure 5F, ISL-1 was recruited to the c-Myc enhancer about four folds as compared with IgG, suggesting that ISL-1 could bind on the c-Myc enhancer in vivo. These results indicate that ISL-1 is a direct regulator of $\mathrm{c}-\mathrm{Myc}$ transcription in NHL cells.

Taken together, ISL-1 promotes NHL cells proliferation possibly via the activation of the c-Myc enhancer and thus increasing its expression.

\section{p-c-Jun and p-STAT3 contribute to the up-regulation of ISL-1 expression in NHL cells}

To explore the molecular regulatory mechanism for ISL-1 up-regulation, bioinformatic analysis was used to identify the potential regulatory factors that could bind on the transcriptional regulatory region of ISL-1. Relevant conserved binding sites of symbolic transcriptional factors, specifically pointing to major pathways such as WNT, MAPK/ERK, p38 MAPK, SAPK/JNK and JAK/STAT, were identified on the ISL-1 transcriptional regulatory region. Previous reports show that ISL-1 is regulated by or interacts with these signal pathways in different physiological or pathological processes and all these signal pathways could contribute to malignant progression of NHLs [19-25]. However, whether the up-regulated expression of ISL-1 in NHLs is mediated by these signal pathways needs to be elucidated.

To explore which signal pathway is involved in ISL-1 up-regulation in NHL, Western blot was used to analyze the impact of inhibitors or activators of the above signaling pathways on ISl-1 expression. The results showed that both JNK signaling inhibitor SP600125 and JAK/STAT signaling inhibitor STATTIC could notably reduce the expression of ISL-1 at protein level. Other inhibitors or activators exhibited little effect on the expression level 


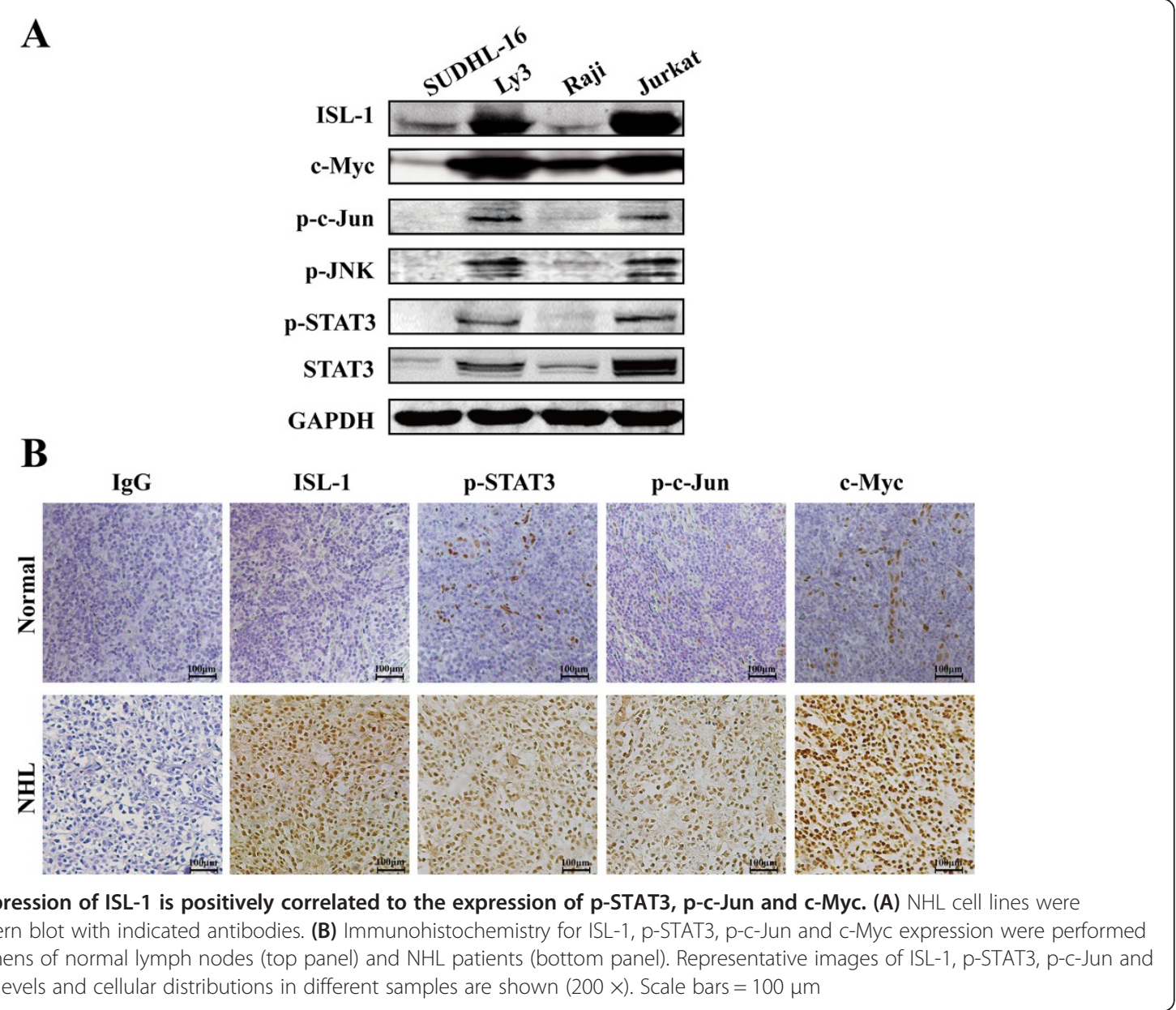

of ISL-1 (Additional file 3: Figure S3). Therefore, we suppose that the expression of ISL-1 may be modulated by JNK and JAK/STAT signal pathways.

As we known, p-c-Jun and p-STAT3 belong to JNK and JAK/STAT signal pathways, respectively. They are the most important functional activators for the signaling transduction and closely link to lymphoma cell survival, proliferation and transformation [21,24,26-29]. To verify how ISL-1 is regulated by JNK and JAK/STAT signal pathways, we first analyzed the basal expression levels and correlations of p-c-Jun, p-STAT3, along with ISL-1 and the prominent oncogenic protein $\mathrm{c}-\mathrm{Myc}$ in a series of NHL cell lines and numbers of human NHL tissue specimens. The results of Western blot showed that the p-c-Jun and p-STAT3 were readily detectable and positive consistent with the expression level of ISL-1 and c-Myc in all these cell lines (Figure 4A). We then analyzed the expression of ISL-1, p-c-Jun, p-STAT3 and cMyc at protein level on 35 cases of human NHL and 10 cases of human normal lymph node by immunohistochemical staining. As shown in Figure 4B, p-c-Jun, p-STAT3 and
c-Myc staining were considerably stronger in NHL than in normal lymph node, in parallel with the pattern observed for ISL-1 in NHL. Pearson correlation analysis revealed that the expression level of ISL-1 protein is strongly correlated with p-STAT3, p-c-Jun and c-Myc protein levels in human NHL samples surveyed (Pearson correlation coefficient $\mathrm{r}=0.737,0.501,0.803$ respectively, all $p<0.001$ ). These data indicate that increased coexpression of ISL-1, p-STAT3, p-cJun and c-Myc may be associated with the development of NHL. The above results indicate that JNK and JAK/STAT signaling pathways are likely to promote ISL-1 expression through the constitutively activated p-c-Jun and p-STAT3.

Further analysis showed that the significantly increased ISL-1 expression was positively associated with the activation of p-c-Jun or p-STAT3, after treated with JNK or JAK/ STAT activator (Anisomycin or IL-6). Conversely, after treated with JNK or JAK/STAT inhibitor (SP600125 or STATTIC), the expression of ISL-1 was obviously decreased (Figure 6). These results show that persistent activation of p-c-Jun and p-STAT3 lead to the aberrant transcription of ISL-1 in NHL cells. 

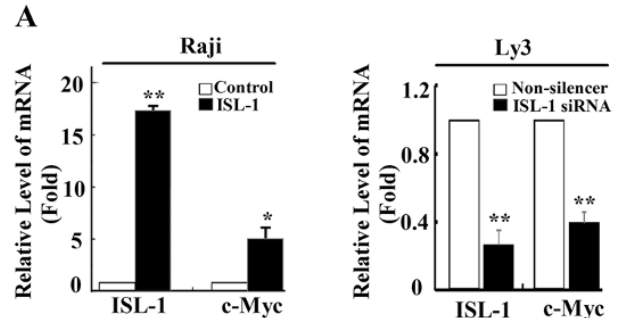

B

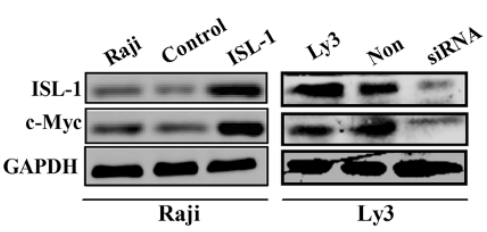

C

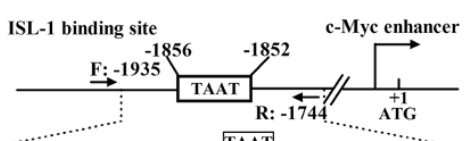

R:

WT

WT human 5' CCAAATTTIAATIIAGCTCAAGACTC 3 '

M1 human 5' ……….............gAT ....................................... $3^{\prime}$

M2 human 5' …………............ggc............................................. $3^{\prime}$

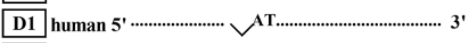

D2 human $^{\prime}$ '...............................................................

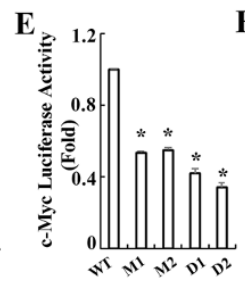

Figure 5 ISL-1 promotes the expression of c-Myc in NHL cell lines. (A to B) The expression of ISL-1 and c-Myc were analyzed at both mRNA and protein levels by real-time RT-PCR (A) and Western blot (B) in Raji cells with stable ISL-1 overexpression and Ly3 cells with stable ISL-1 knockdown. (C) Consensus binding site (TAAT box) for ISL-1 on the human c-Myc enhancer was analyzed by Matlnspector software. The mutant sequences are presented and they were used to construct mutant c-Myc-luc. (D to E) The transcriptional activity of ISL-1 on c-Myc-luc wide type (D), mutants or deletions (E) was analyzed by luciferase reporter assay in HeLa cells. ("WT", "M" and "D" represent the plasmid of c-Myc-luc wide type, mutant, or deletion, respectively.). Non, WT and ctrl served as the control in corresponding experiments. (F) ISL-1 recruited on c-Myc promoter was analyzed by ChIP assay. Soluble chromatin was prepared from Ly3 cells followed by immunoprecipitation with the antibody against ISL-1 and the normal IgG served as a control. The DNA extractions were amplified using the primers that covered the ISL-1 binding sites on c-Myc enhancer region by real-time $P C R$. The data represent 3 independent experiments, each performed in triplicate. Each bar represents mean \pm SD. $p$ values were calculated using a Student $t$-test $\left({ }^{*} p<0.05,{ }^{* *} p<0.01,{ }^{*} p<0.05\right.$ vs. the control).
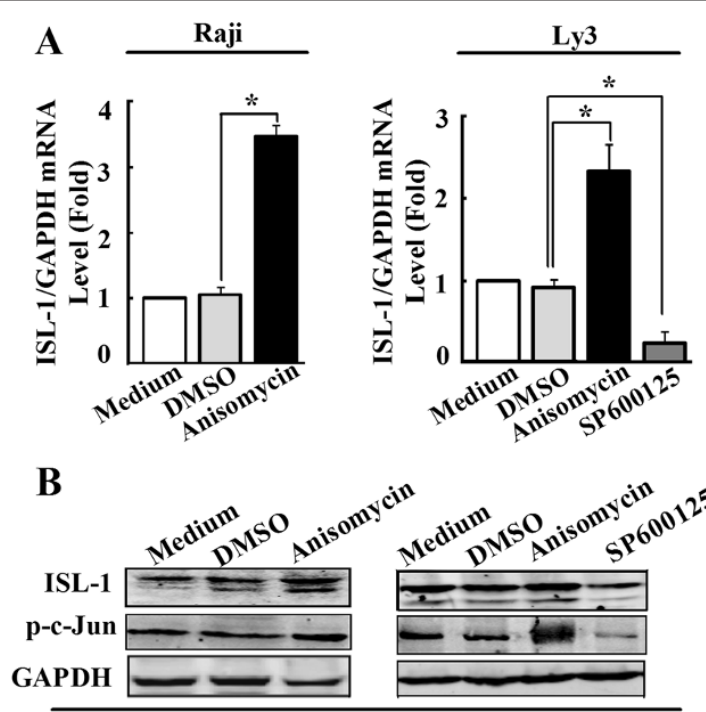

Anisomycin/SP600125

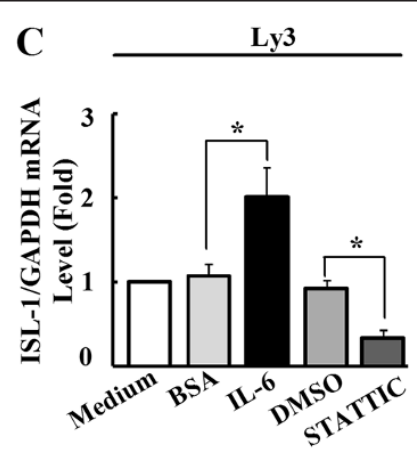

D

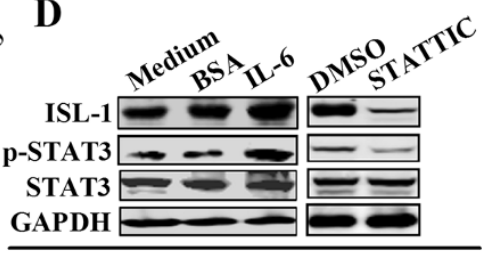

IL-6/STATTIC

Figure 6 p-c-Jun and p-STAT3 contribute to ISL-1 overexpression in NHL cells. (A to B) real-time RT-PCR (A) and Western blot (B) show the expression changes of ISL-1 in Raji and Ly3 cells after treated with JNK signaling pathway activator (Anisomycin, 15 ng/ml) or inhibitor (SP60012, $10 \mu \mathrm{M}$ ) for $6 \mathrm{~h}$. (C to D) real-time RT-PCR (C) and Western blot (D) show the expression changes of ISL-1 in Ly3 cells after treated with JAK/STAT signaling pathway activator $(\mathrm{IL}-6,4 \mathrm{ng} / \mathrm{ml})$ or inhibitor (STATTIC, $6 \mu \mathrm{M})$ for $24 \mathrm{~h}$. Each bar represents mean \pm SD from three samples. $p$ values were calculated using a Student $t$-test ${ }^{*} p<0.05$, vs. the control). 
Inhibition of JNK and JAK/STAT pathways suppresses NHL cells proliferation via down-regulating ISL-1 expression

We have shown that both JNK and JAK/STAT signaling inhibitors can suppress ISL-1 expression. However, it is not clear whether these inhibitors could affect the proliferation of NHL cells by decreasing ISL-1 expression level. CCK-8 analysis was firstly performed to analyze the influence of JNK and JAK/STAT inhibitors on NHL cells proliferation. As shown in Figure 7A, both SP600125 and STATTIC could significantly decrease the proliferation rate of NHL cells.

To further investigate whether ISL-1 was involved in the inhibition of tumor cells proliferation mediated by these inhibitors, Ly3 cells were treated with SP600125 or
STATTIC to inhibit the phosphorylation of c-Jun or STAT3. As shown in Figure 7B, C and (Additional file 4: Figure S4), a distinct decreased expression of ISL-1 was correlated to SP600125 or STATTIC-induced inhibition of p-c-Jun or p-STAT3. Additionally, the expression change of $\mathrm{c}-\mathrm{Myc}$ was also consistent with the change pattern of ISL-1. These data indicate that the JNK and JAK/ STAT pathways regulate c-Myc expression and NHL cells proliferation, which may be partly through the regulation of ISL-1 expression.

To explore this further, luciferase assay was used to analyze the impact of SP600125 or STATTIC on the luciferase activity of $c-M y c-l u c$. The inhibition of JNK and JAK/STAT pathways significantly decreased $c$-Myc-luc

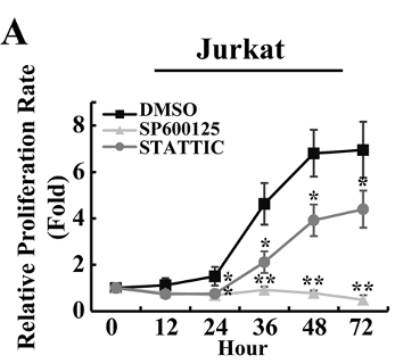

$\mathbf{C}$

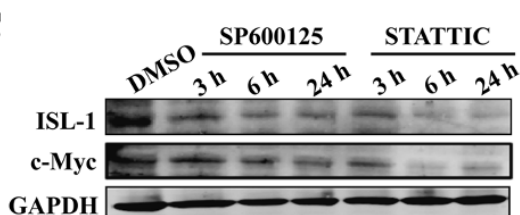

D
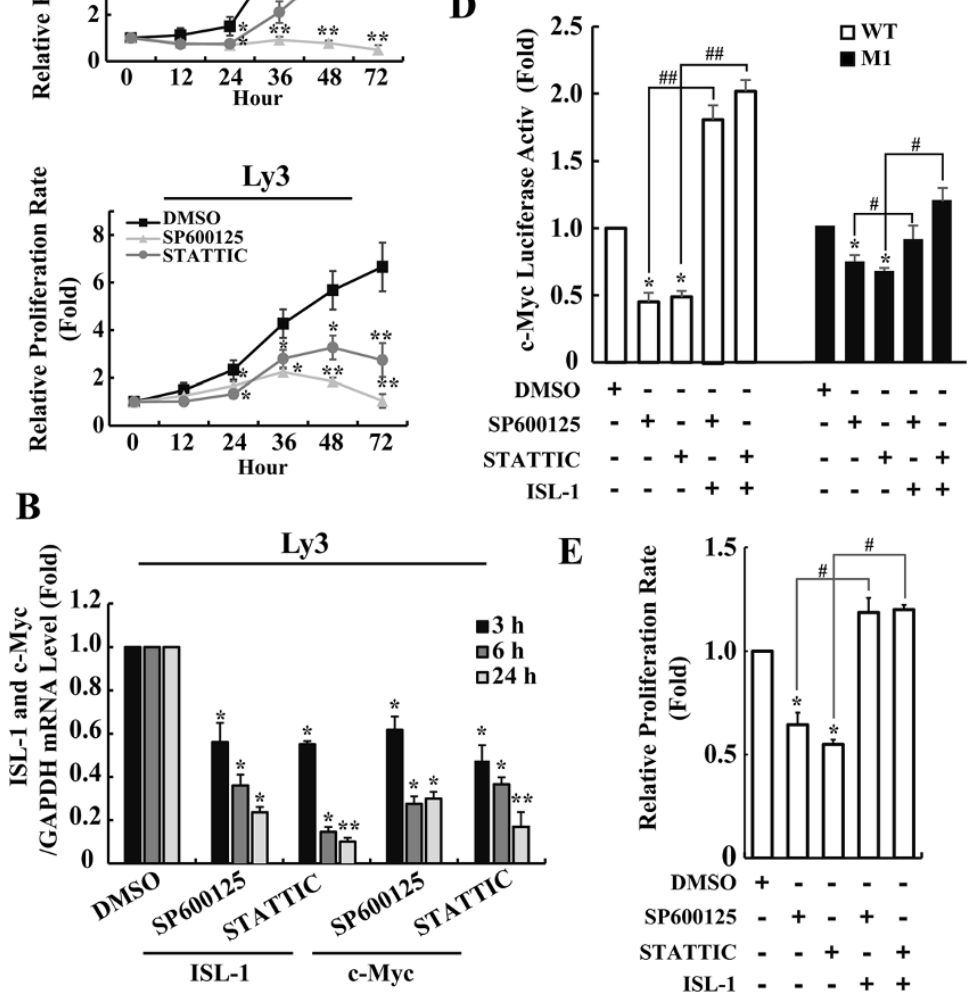

Figure 7 JNK or JAK/STAT signaling inhibitors inhibit NHL cells proliferation through down-regulating ISL-1 expression. (A) The relative proliferation rate of lymphoma cell lines were measured using CCK-8 analysis after treated with JNK signaling pathway inhibitor (SP60012, 10 $\mu$ M) or JAK/STAT signaling pathway inhibitor (STATTIC, $6 \mu \mathrm{M}$ ). The cell treated with DMSO were used as the control. (B to C) The effect of SP600125 $(10 \mu \mathrm{M})$ and STATTIC $(6 \mu \mathrm{M})$ on ISL-1 and c-Myc expression at both mRNA (B) and protein levels (C) were analyzed by real-time RT-PCR and Western blot. The cells treated with DMSO at different time point were used as the corresponding control. (D) The luciferase activity of c-Myc-luc (wide type or M1) was measured in Ly3 cells with or without ISL-1 transcfection after treated with $10 \mu$ M SP600125 or $6 \mu$ M STATTIC for 24 h. (E) The growth inhibition of Ly3 cells with or without ISL-1 transcfection was measured by CCK-8 analysis after treated with $10 \mu \mathrm{M} \mathrm{SP600125} \mathrm{or} 6 \mu$ M STATTIC for $24 \mathrm{~h}$. The data represent three independent experiments. Each bar represents mean \pm SD. $p$ values were calculated using a Student $t$-test $\left({ }^{*} p<0.05\right.$,

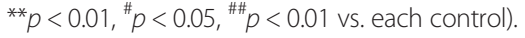


(wild type) activity, and the overexpression of ISL-1 could recover the effect mediated by the inhibitors of JNK and JAK/STAT pathways (Figure 7D left panel). Whereas, the mutant constructs $c$-Myc-luc M1 exhibited much smaller extent of luciferase activity changes (Figure 7D right panel). These results support that ISL-1 is involved in the JNK and JAK/STAT regulation on c-Myc expression. We next assessed whether the expression level of ISL-1 could influence the effects of p-c-Jun and p-STAT3 on the proliferation rate of Ly3 cells. As shown in Figure 7E, both p-c-Jun and p-STAT3 inhibitors could significantly suppress the proliferation of Ly3 cells transfected with the control vectors, while, the growth inhibition mediated by $\mathrm{p}$-c-Jun and p-STAT3 inhibitors could be rescued in ISL-1-overexpressing cells, which further demonstrates the effect of ISL-1 on the proliferation of cells.

Collectively, JNK and JAK/STAT signaling inhibitors suppress NHL cells proliferation possibly through downregulating ISL-1 expression. Therefore, ISL-1 may serve as a new target molecule for NHL treatment.

\section{p-STAT3/p-c-Jun/ISL-1 forms a transcriptional complex and binds directly to the ISL-1 promoter in NHL cells}

The above results have shown that p-STAT3 and p-c-Jun could increase the expression level of ISL-1 to promote the proliferation of NHL cells. However, it is unknown how p-STAT3 and p-c-Jun control ISL-1 expression. Bioinformatic analysis showed that the core transcriptional regulatory region of ISL-1 (-1000 ATG) [30] contains conserved p-STAT3 and p-c-Jun binding sites (Figure 8A). Luciferase assay with ISL-1-luc, a ISL-1 luciferase reporter construct containing the binding site of c-Jun and STAT3, was performed in Ly3 cells treated with IL-6/STATTIC (JAK/STAT signaling activator/inhibitor) or Anisomycin/ SP600125 (JNK signaling activator/inhibitor), respectively. As shown in Figure 8B, ISL-1-luc activity was increased in Anisomycin or IL-6 treated cells. Whereas a significant decrease of ISL-1-luc activity could be observed after SP600125 or STATTIC treatment. These results further demonstrate that both JNK and JAK/STAT signaling pathways are able to activate the ISL-1 transcription effectively.

To confirm whether p-STAT3 and p-c-Jun bind to the ISL-1 regulatory region, a set of primers covering the ISL-1 promoter region between -994 and -216 were designed for real-time PCR in ChIP assay (Figure 8A). The ChIP analysis showed that p-STAT3 was recruited to the region of ISL-1 promoter covered by primer 2 $(-790 \sim-630)$ by approximately 12 folds (Figure 8C left panel), and p-c-Jun was recruited to the region of ISL-1 promoter covered by primer $4(-397 \sim-216)$ by about 6 folds (Figure $8 \mathrm{C}$ right panel), respectively, as compared with primer $1(-994 \sim-772)$ as the control. Interestingly, we also observed magnificent enrichment of p-STAT3 at the p-c-Jun binding region (primer 4 covered region, Figure $8 \mathrm{C}$ left panel), p-c-Jun at the p-STAT3 binding region (primer 2 covered region, Figure $8 \mathrm{C}$ right panel), and both p-STAT3 and p-c-Jun at the primer $3(-613 \sim-373)$ covered region (Figure $8 \mathrm{C}$ left and right panel). Therefore, we suppose that p-STAT3 possibly cooperate with p-c-Jun and synergistically regulate ISL-1 expression in NHL cells.

According to previous reports, p-STAT3 could interact with p-c-Jun to regulate MMP-1 [31], MMP-7 [32] or other genes expression in human cancers [33]. Meanwhile, the cooperation and co-localizations between p-STAT3 and ISL-1 [25,34], p-c-Jun and ISL-1 [23] are also authenticated in different genes transcription. These evidences promote us to hypothesize that p-STAT3, p-c-Jun and ISL-1 may form a transcriptional activation complex that regulates the expression of ISL-1 by direct binding to the ISL-1 promoter.

To verify this hypothesis, co-immunoprecipitation (Co-IP) and ChIP-re-IP were performed to analyze whether $\mathrm{p}$ STAT3, p-c-Jun and ISL-1 could form a complex and bind directly on the ISL-1 promoter. Co-IP results demonstrate that one component of the presumptive complex could co-immunoprecipitate with all of the other components, supporting the existence of this complex (Figure 8D). Furthermore, ChIP-re-IP analysis confirmed that p-STAT3, p-c-Jun and ISL-1 indeed existed in the same protein complex and co-localized on the primer 2 and primer 4 covered region of ISL-1 promoter (Figure $8 \mathrm{E}$ ). These results reveal that p-STAT3, p-c-Jun and ISL-1 could form a transcriptional activation complex on the ISL-1 promoter, which further indicates that there might be a positive feedback loop to contribute to ISL-1 up-regulated expression in NHL cells.

To determine whether ISL-1 is involved in the positive feedback loop on the ISL-1 transcription, luciferase assay was performed with ISL-1-luc. As shown in Figure 8F, ISL1-luc activity was increased in a dose-dependent manner in ISL-1-overexpressing Ly3 cells, indicating, for the first time, that ISL-1 could promote its own expression in NHL cells and therefore to form a positive feedback.

Collectively, these results indicate that ISL-1 may have a positive feedback regulation: p-STAT3 and p-c-Jun upregulate ISL-1 expression, then ISL-1 form a complex with p-STAT3 and p-c-Jun to participate ISL-1 overexpression. The consequence is to promote the proliferation of NHL cells.

\section{Discussion}

NHL is the most common lymphoid malignancy in adults, accounting for $\sim 70,000$ new cases each year in the US [2]. The aggressive NHL, which is, pathophysiologically and clinically, a very heterogeneous disease, differs significantly in its dependence on signaling pathways, and responses 


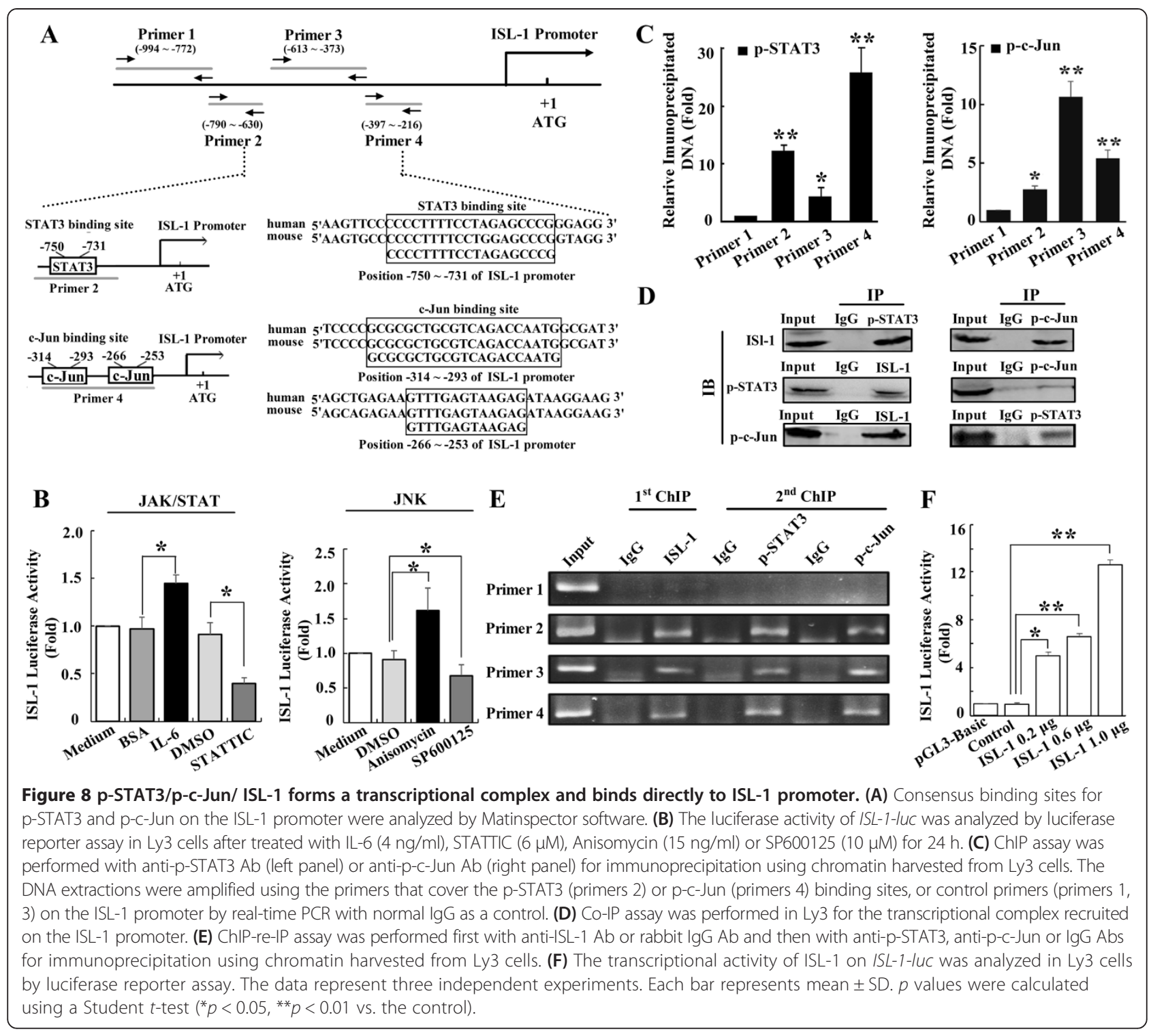

differently to current standard therapies [35]. Therefore, a common molecular target functionally associated with non-Hodgkin lymphomagenesis is required to be identified to develop effective therapeutic approaches that will improve the clinical outcome of patients with different subtypes of NHL. In this study, we found that an elevated expression of ISL-1 in $75 \%$ of NHL samples examined, and further studies provided evidences that aberrant expression of ISL-1 significantly correlated with NHLs and might be a potential therapeutic target for NHL treatment. However, the classification of NHL is very complicated. According to the World Health Organization (WHO) Classification, NHL could be classified into 36 subtypes (21 of B cell and 15 of T-cell type), excluding entities of uncertain malignant potential [1]. The most dominant forms of NHL are diffuse large B-cell lymphoma (about 30\%) and follicular lymphoma (about 20\%).
All other NHL subtypes have a frequency of less than $10 \%$ [1]. In parallel with the proportion of each NHL subtype, we performed immunohistochemical analyses for ISL-1 in 195 primary lymphoma tissue specimens, including 159 B-cell lymphoma and 36 T-cell lymphoma samples. As summarized in Table 1, ISL-1 was remarkably overexpressed in $81 \%$ of 139 DLBCL samples. Meanwhile, although strong positive staining for ISL-1 was identified in $25 \%$ of 8 follicular lymphoma (FL) and $67 \%$ of 3 Burkitt lymphoma samples, respectively, the total numbers of those specimens examined were small and awaited larger confirmatory studies. In the further study, we applied the commonly used Raji (Burkitt cell line), Jurkat (T-cell leukemia/lymphoma cell line) and Ly3 (DLBCL cell line) in multiple experiments to represent NHLs [24,36,37]. However, it should not be ignored that the molecular pathogenesis of each subtype are not completely identical, 
which may be the possible reasons for the $25 \%$ of ISL-1 negative NHLs. Moreover, it has been reported that in addition to de novo DLBCL, 30-40\% of FL, a low-grade $\mathrm{NHL}$, will transform to an aggressive DLBCL $[38,39]$. According to the immunohistochemical analyses, we were able to show a significantly elevated level of ISL-1 in the vast majority $(81 \%)$ of DLBCL. In contrast, we did not observe significant changes of ISL-1 in most of the indolent lymphoid malignancies examined, such as FL (25\%), indicating that ISL-1 expression level might be correlated with the progression and degree of malignant NHLs.

We previously showed that ISL-1 could stimulate pancreatic islet cells growth and prevent adult pancreatic islet cells from reactive oxygen species (ROS) induced apoptosis [6]. In this study, we found that abnormally up-regulated expression of ISL-1 in NHL cells obviously facilitated cell proliferation in vitro and significantly enhanced lymphoma development in vivo, providing the first evidence that ISL-1 could promote non-Hodgkin lymphomagenesis and specific disruption of ISL-1 could be capable of inhibiting NHL cells with high endogenous levels of ISL-1. Our previous report reveals that c-Myc and CyclinD1 are novel downstream targets of ISL-1 and are involved in ISL-1 regulation on the proliferation of adult islet cells [6]. However, in NHL cells, ISL-1 could regulate c-Myc but had minimal effect on CyclinD1. These implied that c-Myc must be a more potent downstream factor of ISL-1 to mediate proliferation effects in lymphoma tumorigenesis.

The proto-oncogene c-Myc has been linked to a diverse range of cellular functions, such as cell cycle regulation, proliferation, differentiation and metabolism. Not surprisingly, aberrant c-Myc signaling has been observed to promote cell transformation and tumor progression in human cancers [40]. According to previous reports, c-Myc overexpression has not only been described as a defining feature and the driving oncogene for Burkitt lymphoma, but also been recognized in mantle cell lymphoma (MCL), DLBCL and other NHLs [18,41-43]. c-Myc overexpression in human tumors has been attributed to transcriptional regulation, gene amplification, as well as genomic translocation [40]. However, in most NHLs, the reason for c-Myc up-regulated expression has not been clearly elucidated. In this study, we show that ISL-1 is recruited to the transcriptional region of the cMyc gene and activate its expression, which shed light on the mechanism underlying the c-Myc dysregulation and clinical lymphomagenesis.

The c-Jun N-terminal kinase (JNK) [21,26,28] and Janus kinase/signal transducer and activator of transcription (JAK/STAT) [29,44-47] signaling pathways, which are predicted to modulate ISL-1 expression, have been reported to link to the oncogenic process of a variety of lymphoma subtypes, making them appealing targets for pathway- directed cancer therapy. The application of specific signaling pathways' activators and inhibitors demonstrated the correlation between JNK pathway and ISL-1, as well JAK/STAT pathway and ISL-1 expression [21,24]. Figure 6 showed that ISL-1 expression was increased by elevated c-Jun and STAT3 phosphorylation in Raji and Ly3 cells, respectively. Reciprocally, attenuated p-c-Jun and p-STAT3 in these cells resulted in a decreased expression of ISL-1. Furthermore, Pearson correlation analysis also revealed strong correlation between the expression level of ISL-1 with p-STAT3 and p-c-Jun protein level in human NHL samples. These data unequivocally linked ISL-1 expression level with JNK and JAK/STAT signaling pathways.

Many reports suggest that c-Myc is a downstream effector of JNK or STAT3 signaling and c-Myc protein level in NHL cells could be reduced in the presence of JNK-specific siRNA or STAT3 shRNA [21,24]. However, it remains to be determined whether p-c-Jun and p-STAT3 regulate the c-Myc expression directly or indirectly. Interestingly, our data suggested that JNK and JAK/STAT pathways could corporately regulate c-Myc expression and promote lymphoma growth through up-regulating the level of ISL-1. The overexpression of ISL-1 could rescue the growth suppression effect mediated by JNK and JAK/STAT inhibitors, indicating that ISL-1 is necessary for p-c-Jun and p-STAT3 effects. Therefore, ISL-1 might be an important common mediator of c-Myc and JNKJAK/STAT signaling pathways in the progression of NHL. In terms of regulatory mechanism of NHL, we demonstrated that ISL-1 expression was regulated by both JNK and JAK/STAT signaling pathways, p-STAT3/p-c-Jun/ISL1 could form a transcriptional complex and bind directly to the ISL-1 promoter, indicating that ISL-1 might has a positive feedback regulation. These conclusions are consistent with previous reports that striking coincidences for concerted aberrant activation of both STAT3 and c-Jun in human cancer specimens are observed [31], and c-Jun or c-Myc is required for the transforming activity of STAT3 in tumorgenesis $[32,48]$. Taken together, our results reveal a functional linkage between JNK and JAK/STAT signaling and the oncogenic roles of ISL-1 and c-Myc in NHL.

\section{Conclusions}

Overall, in this study, we extend the knowledge about the crucial roles of ISL-1. Our findings document that ISL-1 is highly expressed in NHL and plays an oncogenic role in lymphomagenesis. Aberrant ISL-1 could stimulate cell proliferation and xenograft growth by activating c-Myc transcription. Moreover, JNK and JAK/STAT pathways contribute to ISL-1 dysregulation. Our study identifies a specific and novel function of ISL-1 in NHL development and suggests that the ISL-1 suppression represents a potential target for NHL treatment. 


\section{Materials and methods} Immunohistochemistry and immunohistologic analysis All human samples were obtained from the Department of Pathology, School of Basic Medical Sciences, Peking University with the informed consent and with the approval from the Research Ethics Committee of Peking University (IRB 00001052-13014). The lymphoma tissue microarrays (TMA) 203a and LY2086a were bought from US Biomax (Rockville, MD, USA). Collected specimens and TMA were subjected to immunohistochemistry (IHC) analysis using the Enovision Detection Kit/DAB (GK50 0705, DAKO A/S, Glostrup, Denmark) according to the manufacturer's protocol with the indicated antibody: mouse monoclonal anti-ISL-1 (ab86472, Abcam, Hong Kong, China); rabbit polyclonal anti-c-Myc and antiphospho-c-Jun (Ser63) (E1A1002 and E1A3089, EnoGene, China); rabbit monoclonal anti-phospho-Stat3 (Tyr705) (\#9145, Cell Signaling Technology, Beverly, MA, USA). Monoclonal mouse IgG2a and ployclonal rabbit IgG (X0943 and X0936, DAKO A/S, Glostrup, Denmark) were used as isotope controls.

A total of 10 to 20 areas (depending on the size of the section) at $400 \times$ magnification of each section were examined under microscopy, and the immunostaining was assessed by two researchers independently in a blinded fashion, i.e., without the knowledge of clinic pathologic information. The expression level of ISL-1 in lymphomas was scored semi-quantitatively based on the percentage of positive cells and classified into negative $(<25 \%$ neoplastic cells stained positive), weak ( $25 \sim 49 \%$ neoplastic cells stained positive), moderate ( $50 \sim 75 \%$ neoplastic cells stained positive) and strong staining ( $>75 \%$ neoplastic cells stained positive), which represent the score of $0,1,2$ and 3. The images were acquired with a Leica DM25000B microscope (Leica, Germany). The association between immunoreactivity and patient clinic pathological parameters was assessed by $\chi^{2}$ test. Positive percent was determined by number of strong staining samples (with ISL-1 expression level scored 2 or 3 ) over the total number of samples.

\section{Cell culture and the establishment of stable cell lines}

Diffuse large B cell lymphoma cell lines SUDHL16 and Ly3 (gifts from Prof. Zhu J, Peking University Cancer Hospital), Burkitt lymphoma cell lines (Raji, preserved by our laboratory, and Ramos purchased from Cell Resource Center of Shanghai Institutes for Biological Science, Shanghai, China), T-cell leukemia/lymphoma cell line Jurkat (kindly provided by Prof. Ma DL, Peking University School of Basic Medical Sciences) were grown in RPMI 1640 containing 10\% fetal bovine serum. HeLa cells (preserved by our laboratory) were cultured in Dulbecco's modified eagle medium supplemented with $10 \%$ fetal calf serum.
To establish stable cell lines with ISL-1 overexpressing, Raji, Ly3 and Jurkat cells were transfected with $10 \mu \mathrm{g}$ pcDNA3.1-ISL1 plasmid [6], or a control pcDNA3.1 plasmid, at a density of $1 \times 10^{7} / \mathrm{ml}$, in a $0.2 \mathrm{~cm}$ cuvette (BTX) using an BTX ECM803 Electroporator (Genetronics, San Diego, CA, USA) at 130 V, 20 ms. G418 selection $(1000 \mu \mathrm{g} / \mathrm{ml})$ was performed $48 \mathrm{~h}$ after transfection. The cells were cultured for about 21 days to obtain stable cell lines. The culture medium containing G418 was changed every two days. To establish stable knockdown cell lines, Ly3 and Jurkat cells were electroporated with pLL3.7-ISL1siRNA or pLL3.7-nonsilencer, respectively [6], and $48 \mathrm{~h}$ after transfection, cells were cultured with a puromycincontaining medium $(0.5 \mu \mathrm{g} / \mathrm{ml})$ for about 21 days.

\section{Cell treatment, cell proliferation and cell cycle assays}

STATTIC (sc-202818, Santa Cruz Biotechnology, Santa Cruz, CA, USA), SP600125 (s5567) and Anisomycin (A9789) purchased from Sigma (Louis, MO, USA) were dissolved in $100 \%$ dimethyl sulfoxide to prepare a $40 \mathrm{mM}$ stock, $20 \mathrm{mM}$ stock and $15 \mathrm{mg} / \mathrm{ml}$ stock respectively, and stored at $-20^{\circ} \mathrm{C}$. Recombinant human interleukin (IL)-6 purchased from R \& D Systems (206IL, Minneapolis, MN, USA) was reconstituted in sterile PBS containing $0.1 \%$ bovine serum albumen to prepare a $10 \mu \mathrm{g} / \mathrm{ml}$ stock and stored at $-20^{\circ} \mathrm{C}$. The stock solution was added in culture medium to achieve the indicated final concentrations for cell culture.

The cell proliferation was examined using a CCK-8 cell proliferation kit (Dojindo Laboratories, Kumamoto, Japan), according to the instruction from the supplier. Absorbance was measured at $450 \mathrm{~nm}$ with Microplate Reader (Bio-Rad, La Jolla, CA, USA). After 24 hr serum depletion $(0.2 \% \mathrm{FBS})$, cells were subsequently incubated in $10 \%$ FBS medium for an additional $24 \mathrm{hr}$ before harvest. Cell cycle assessment and data analysis were carried out referring to our previous report [6] using FACS Calibur flow cytometry (Becton Dickinson, Franklin Lakes, NJ, USA) equipped with the ModiFit LT v2.0 software.

\section{Animal experiments}

The animal experiments were performed in accordance with the ethical principles and guidelines for scientific experiments on animals of the Swiss Academy of Medical Sciences (1995). All protocols were approved by the Animal Care and Use Committee of Peking University (LA 2010-066). Five-week-old NOD/SCID (nonobese diabetic/severe combined immune deficient) mice were purchase from the Department of Laboratory Animal Science of Peking University. Six or five mice per group were injected subcutaneously into the left and right oxter flank with $1 \times 10^{7}$ cells resuspended in $200 \mu \mathrm{l}$ PBS. All mice were maintained under specific pathogen-free conditions. Tumors were measured at indicated time 
with calipers and tumor volumes were calculated as $1 / 2 \times$ length $\times$ width $^{2}$. The mice were sacrificed by euthanasia just before tumor skin festering and the tumors were collected for further analysis. The significance of differences between groups was determined using the 2-way ANOVA.

\section{Luciferase assays}

The plasmid transfection and luciferase activity detection were performed as described before [30]. ISL-1-luc plasmid was constructed previously by our laboratory [30]. pCDNA3.1-c-Myc, $c-M y c-l u c$ was kindly provided by Prof. Shang YF, Peking University School of Basic Medical Sciences. $c$-Myc-luc M1, M2, D1 and D2 were commercially constructed by TransGen Biotech (Beijing, China).

\section{RT-PCR and real-time RT-PCR}

Total RNA was extracted using Trizol Reagent (Invitrogen, Carlsbad, CA, USA) based on the manufacturer's instructions. RT-PCR and real-time RT-PCR amplifications were performed as descripted before [30] with different primers: ISL-1: F: 5'-CTGCTTTTCAGCAACTGGTCA3', R: 5'-TAGGACTGGCTACCATGCTGT-3'; c-Myc: F: 5'-GCCACGTCTCCACACATCAG-3', R: 5' -TCTTGGC AGCAGGATAGTCCTT-3'; GAPDH: F: 5'-CGACCAC TTTGTCAAGCTCA-3', R: 5'-AGGGGTCTACATGGC AACTG-3'.

\section{Immunoprecipitation and Western blot analysis}

Cell lysates were prepared using RIPA lysis buffer (P0013E, Beyotime, Shanghai, China), which included protease and phosphatase inhibitors (469313200, 14906845001, Roche, Basle, Switzerland). Immunoprecipitation and Western blot analysis were carried out as described before using the indicated antibody [49]. Mouse monoclonal antiISL-1 (H00003670-M05, Abnova, Taipei, China); rabbit monoclonal anti-ISL-1 (3727-1, Eptomics an abcam company, Hong Kong, China); rabbit monoclonal antiphosphor-JNK (Thr163/Tyr165) (\#4668), rabbit monoclonal anti-c-Myc (\#5605), rabbit monoclonal anti-STAT3 and anti-phospho-STAT3 (Tyr705) (\#4904 and \#9145), rabbit monoclonal anti-GAPDH (\#2118) and anti- $\beta$ tubulin (\#2146) were all purchased from Cell Signaling Technology (Beverly, MA, USA). Mouse monoclonal antiphospho-c-Jun (Ser63) (sc-822) and rabbit polyclonal anti-c-Myc (sc-764) were obtained from Santa Cruz Biotechnology (Santa Cruz, CA, USA).

\section{Chromatin immunoprecipitation (ChIP) and ChIP-re-IP assays} ChIP and ChIP-re-IP experiments were performed in Ly3 cells according to the method described by Zhang $\mathrm{Y}$ et al. [50] using primers covering ISL-1 promoter region: Primer 1: F: 5'-CCTTTCCTCCCACCCAACGTTTTTA3', R: 5'-GCTTGGTTTGGTCCCCACG-3'; Primer 2: F:
5'-GTGGGGACCAAACCAAGCTGAAC-3', R: 5'-GGT CCCCGCAGTCCGGCT-3'; Primer 3: F: 5'-AGGAGC AGCGCCACAGGAG-3', R: 5' -ATTATCATATTTCAGC CTCGCCGC-3'; Primer 4: F: 5'-GCGGCGAGGCTGA AATATGATAAT-3', R: 5'-GCAGACTCGGCGCGGCT C-3'; or primer covering c-Myc enhancer region: cMyc: F: 5' -TACAGTGCACTTTCACTAGTATTCA-3', R: 5' -TTATTGGAAATGCGGTCATG-3'.

\section{Statistical analysis}

Statistical analyses were carried out using the statistical software SPSS 17.0. The data are expressed as means \pm standard deviation (S.D.). Differences were considered to be statistically significant at $p<0.05$.

\section{Additional files}

\begin{abstract}
Additional file 1: Figure S1. ISL-1 is efficiently overexpressed or knockdown in stably transfected NHL cells. ISL-1 expression was detected by Western blot analysis in stably transfected Raji (A), Ly3 (B) and Jurkat (C) cells. GAPDH served as an internal control. Representative images are shown (A to $\mathbf{C}$ top panel) and the degree of ISL-1 expression changes was calculated by gray scanning ( $\mathbf{A}$ to $\mathbf{C}$ bottom panel) using the Bio-Rad Quantity One software on the Western images from 3 independent experiments. Each bar represents mean \pm SD. $p$ values were calculated using a Student $t$-test $\left({ }^{*} p<0.05,{ }^{* *} p<0.01, \# \#<0.01, \# \# p<0.001\right)$.

Additional file 2: Figure S2. The ISL-1-overexpressing or -knockdown cells produce significantly larger or smaller tumors than the control or non-silencer cells. NOD-SCID mice were injected s.c. with different NHL cells that were stably transfected with pcDNA3.1 (Control), or pCDNA3.1-ISL-1 (ISL-1) construct $(\mathbf{A}, \mathbf{C})$, pLL3.7-Non-silencer or pLL3.7-ISL1-siRNA plasmid $(B, D)$. The mice were killed after the last measurement of tumor volume and the tumors were isolated and weighed. Statistical analysis was carried out with 2-way ANOVA $\left({ }^{*} p<0.05,{ }^{* *} p<0.01\right)$
\end{abstract}

Additional file 3: Figure S3. ISL-1 expression level can be specifically regulated by JNK and JAK/STAT signaling pathways. Western blot showed the expression changes of ISL-1 in NHL cells after treated with WNT signaling pathway inhibitor or activator (Frizzle, $10 \mu \mathrm{M}$ or WNT3a protein, $100 \mathrm{ng} / \mathrm{ml}$ ), MAPK/ERK signaling pathway inhibitor (PD98059, $10 \mu \mathrm{M}$ ), P38/MAPK signaling pathway inhibitor (SB203580, $10 \mu \mathrm{M}$ ), SAPKJNK signaling pathway inhibitor (SP600125, $10 \mu \mathrm{M})$, or JAK/STAT signaling pathway inhibitor (STATTIC, $6 \mu \mathrm{M}$ ) for $24 \mathrm{~h}$. The degree of ISL-1 expression changes was calculated by gray scanning using the Bio-Rad Quantity One software on the Western images. The data represent three independent experiments, each performed in triplicate. Each bar represents mean $\pm \mathrm{SD}\left({ }^{*} \mathrm{p}<0.05\right)$.

Additional file 4: Figure S4. The phosphorylation of c-Jun or STAT3 can be inhibited by the specific JNK or JAK/STAT signaling pathway inhibitor, respectively. Ly3 cells were treated with JNK signaling pathway inhibitor $(\mathrm{SP} 60012,10 \mu \mathrm{M})$ or JAKJSTAT signaling pathway inhibitor (STATTIC, $6 \mu \mathrm{M}$ ) for indicated time. The inhibitory effect of SP600125 on c-Jun phosphorylation (A) and the inhibitory effect of STATTIC on P-STAT3 phosphorylation (B) were analyzed by Western blot. GAPDH served as an internal control.

Competing interests

The authors declare no conflict of interests.

\section{Authors' contributions}

QZ, WW and CZ conceived and designed the experiments; QZ, ZY and CG performed the experiments and analyzed the data; PC, KM, ZJ, HL and $\mathrm{CL}$ contributed reagents/materials/analysis tools; $Q Z, Z Y, W W$ and $C Z$ wrote the paper. All authors read and approved the final manuscript. 


\section{Acknowledgments}

This work was supported by the National Natural Science Foundation of China (No. 81071675, 81170713, 81370236), the Natural Science Foundation of Beijing (No.5122021), Leading Academic Discipline Project of Beijing Education Bureau, and the 111 Project of China (B07001). We thank Prof. Zhu Jun, Peking University Cancer Hospital, China, for generously providing Ly3 and SUDHL16 cell lines; Prof. Ma Dalong, Peking University School of Basic Medical Sciences, China, for generously providing Jurkat cell line and Prof. Shang Yongfeng, Peking University of Basic Medical Sciences, China, for generously providing pCDNA3.1-c-Myc and c-Myc-luc plasmid. We also thank Prof. Wang Wengong and Du Xiaojuan, Peking University School of Basic Medical Sciences, China, for their useful discussion during the course of the study.

\section{Author details}

'Department of Biochemistry and Molecular Biology, School of Basic Medical Sciences, Key Laboratory of Molecular Cardiovascular Sciences, Ministry of Education of China, Peking University, 38 Xueyuan Road, 100191 Beijing China. ${ }^{2}$ Department of Pathology, School of Basic Medical Sciences, Peking University, 38 Xueyuan Road, 100191 Beijing, China.

Received: 26 April 2014 Accepted: 22 July 2014

Published: 29 July 2014

\section{References}

1. Ekstrom-Smedby K: Epidemiology and etiology of non-Hodgkin lymphoma-a review. Acta Oncol 2006, 45:258-271.

2. Siegel R, Ma J, Zou Z, Jemal A: Cancer statistics, 2014. CA Cancer J Clin 2014, 64:9-29.

3. Bu L, Jiang X, Martin-Puig S, Caron L, Zhu S, Shao Y, Roberts DJ, Huang PL, Domian IJ, Chien KR: Human ISL1 heart progenitors generate diverse multipotent cardiovascular cell lineages. Nature 2009, 460:113-117.

4. Roy A, Francius C, Rousso DL, Seuntjens E, Debruyn J, Luxenhofer G, Huber AB, Huylebroeck D, Novitch BG, Clotman F: Onecut transcription factors act upstream of IsI 1 to regulate spinal motoneuron diversification. Development 2012, 139:3109-3119.

5. Wilfinger A, Arkhipova V, Meyer D: Cell type and tissue specific function of islet genes in zebrafish pancreas development. Dev Biol 2013, 378:25-37.

6. Guo T, Wang W, Zhang H, Liu Y, Chen P, Ma K, Zhou C: ISL1 promotes pancreatic islet cell proliferation. PLoS One 2011, 6:e22387.

7. Barzelay A, Ben-Shoshan J, Entin-Meer M, Maysel-Auslender S, Afek A, Barshack I, Keren G, George J: A potential role for islet-1 in post-natal angiogenesis and vasculogenesis. Thromb Haemost 2010, 103:188-197.

8. Luo ZL, Sun H, Yang ZQ, Ma YH, Gu Y, He YQ, Wei D, Xia LB, Yang BH, Guo T: Genetic variations of ISL1 associated with human congenital heart disease in Chinese Han people. Genet Mol Res 2014, 13:1329-1338.

9. Liu J, Walp ER, May CL: Elevation of transcription factor Islet-1 levels in vivo increases beta-cell function but not beta-cell mass. Islets 2012, 4:199-206.

10. Schmitt AM, Riniker F, Anlauf M, Schmid S, Soltermann A, Moch H, Heitz PU, Kloppel G, Komminoth P, Perren A: Islet 1 (IsI1) expression is a reliable marker for pancreatic endocrine tumors and their metastases. Am J Surg Pathol 2008, 32:420-425.

11. Watanabe T, Miura T, Degawa Y, Fujita Y, Inoue M, Kawaguchi M, Furihata C: Comparison of lung cancer cell lines representing four histopathological subtypes with gene expression profiling using quantitative real-time PCR. Cancer Cell Int 2010, 10:2.

12. Ronneberg JA, Fleischer T, Solvang HK, Nordgard SH, Edvardsen H, Potapenko I, Nebdal D, Daviaud C, Gut I, Bukholm I, Naume B, Børresen-Dale AL, Tost J, Kristensen $\mathrm{V}$ : Methylation profiling with a panel of cancer related genes: association with estrogen receptor, TP53 mutation status and expression subtypes in sporadic breast cancer. Mol Oncol 2011, 5:61-76.

13. Hansel DE, Rahman A, Hidalgo M, Thuluvath PJ, Lillemoe KD, Shulick R, Ku J Park JG, Miyazaki K, Ashfaq R, Wistuba II, Varma R, Hawthorne L, Geradts J, Argani $P$, Maitra A: Identification of novel cellular targets in biliary tract cancers using global gene expression technology. Am J Pathol 2003, 163:217-229.

14. Graham RP, Shrestha B, Caron BL, Smyrk TC, Grogg KL, Lloyd RV, Zhang L: Islet-1 is a sensitive but not entirely specific marker for pancreatic neuroendocrine neoplasms and their metastases. Am J Surg Pathol 2013 37:399-405.

15. Campo E, Swerdlow SH, Harris NL, Pileri S, Stein H, Jaffe ES: The 2008 WHO classification of lymphoid neoplasms and beyond: evolving concepts and practical applications. Blood 2011, 117:5019-5032.
16. Gladkikh A, Potashnikova D, Korneva E, Khudoleeva O, Vorobjev I: Cyclin D1 expression in B-cell lymphomas. Exp Hematol 2010, 38:1047-1057.

17. Baron BW, Anastasi J, Montag A, Huo D, Baron RM, Karrison T, Thirman MJ, Subudhi SK, Chin RK, Felsher DW, Fu YX, McKeithan TW, Baron JM: The human BCL6 transgene promotes the development of lymphomas in the mouse. Proc Natl Acad Sci U S A 2004, 101:14198-14203.

18. Zhao X, Lwin T, Zhang X, Huang A, Wang J, Marquez VE, Chen-Kiang S, Dalton WS, Sotomayor E, Tao J: Disruption of the MYC-miRNA-EZH2 loop to suppress aggressive B-cell lymphoma survival and clonogenicity. Leukemia 2013, 27:2341-2350.

19. Ge X, Wang X: Role of Wnt canonical pathway in hematological malignancies. J Hematol Oncol 2010, 3:33.

20. Lin L, Cui L, Zhou W, Dufort D, Zhang X, Cai CL, Bu L, Yang L, Martin J, Kemler R, Rosenfeld MG, Chen J, Evans SM: Beta-catenin directly regulates Islet1 expression in cardiovascular progenitors and is required for multiple aspects of cardiogenesis. Proc Natl Acad Sci U S A 2007, 104:9313-9318.

21. Gururajan M, Chui R, Karuppannan AK, Ke J, Jennings CD, Bondada S: C-Jun N-terminal kinase (JNK) is required for survival and proliferation of B-lymphoma cells. Blood 2005, 106:1382-1391.

22. Dai B, Zhao XF, Mazan-Mamczarz K, Hagner P, Corl S, Bahassi el M, Lu S, Stambrook PJ, Shapiro P, Gartenhaus RB: Functional and molecular interactions between ERK and CHK2 in diffuse large B-cell lymphoma. Nat Commun 2011, 2:402

23. Zhang T, Liu J, Zhang J, Thekkethottiyil EB, Macatee TL, Ismat FA, Wang F, Stoller JZ: Jun is required in Isl1-expressing progenitor cells for cardiovascular development. PLOS One 2013, 8:e57032.

24. Scuto A, Kujawski M, Kowolik C, Krymskaya L, Wang L, Weiss LM, Digiusto D, Yu H, Forman S, Jove R: STAT3 inhibition is a therapeutic strategy for ABC-like diffuse large B-cell lymphoma. Cancer Res 2011, 71:3182-3188.

25. Hao A, Novotny-Diermayr V, Bian W, Lin B, Lim CP, Jing N, Cao X: The LIM/ homeodomain protein Islet1 recruits Janus tyrosine kinases and signal transducer and activator of transcription 3 and stimulates their activities. Mol Biol Cell 2005, 16:1569-1583.

26. Troen G, Nygaard V, Jenssen TK, Ikonomou IM, Tierens A, Matutes E, Gruszka-Westwood A, Catovsky D, Myklebost O, Lauritzsen G, Hovig E, Delabie J: Constitutive expression of the AP-1 transcription factors c-jun junD, junB, and c-fos and the marginal zone B-cell transcription factor Notch2 in splenic marginal zone lymphoma. J Mol Diagn 2004, 6:297-307.

27. Koskela HL, Eldfors S, Ellonen P, van Adrichem AJ, Kuusanmaki H, Andersson El, Lagstrom S, Clemente MJ, Olson T, Jalkanen SE, Majumder MM, Almusa H, Edgren H, Lepistö M, Mattila P, Guinta K, Koistinen P, Kuittinen T, Penttinen K, Parsons A, Knowles J, Saarela J, Wennerberg K, Kallioniemi O, Porkka K, Loughran TP Jr, Heckman CA, Maciejewski JP, Mustjoki S: Somatic STAT3 mutations in large granular lymphocytic leukemia. N Engl J Med 2012, 366:1905-1913.

28. Granato M, Santarelli R, Lotti LV, Di Renzo L, Gonnella R, Garufi A, Trivedi P, Frati L, D'Orazi G, Faggioni A, Cirone M: JNK and macroautophagy activation by Bortezomib has a pro-survival effect in primary effusion lymphoma cells. PLoS One 2013, 8:e75965.

29. Huang X, Meng B, lqbal J, Ding BB, Perry AM, Cao W, Smith LM, Bi C, Jiang C, Greiner TC, Weisenburger DD, Rimsza L, Rosenwald A, Ott G, Delabie J, Campo E, Braziel RM, Gascoyne RD, Cook JR, Tubbs RR, Jaffe ES, Armitage JO, Vose JM, Staudt LM, McKeithan TW, Chan WC, Ye BH, Fu K: Activation of the STAT3 Signaling Pathway Is Associated With Poor Survival in Diffuse Large B-Cell Lymphoma Treated With R-CHOP. J Clin Oncol 2013, 31:4520-4528.

30. Liu Y, Li Y, Li T, Lu H, Jia Z, Wang W, Chen P, Ma K, Zhou C: POU homeodomain protein OCT1 modulates islet 1 expression during cardiac differentiation of P19CL6 cells. Cell Mol Life Sci 2011, 68:1969-1982

31. Zugowski C, Lieder F, Muller A, Gasch J, Corvinus FM, Moriggl R, Friedrich K: STAT3 controls matrix metalloproteinase- 1 expression in colon carcinoma cells by both direct and AP-1-mediated interaction with the MMP-1 promoter. Biol Chem 2011, 392:449-459.

32. Shi M, Liu D, Duan H, Han C, Wei B, Qian L, Chen C, Guo L, Hu M, Yu M, Song L, Shen B, Guo N: Catecholamine up-regulates MMP-7 expression by activating AP-1 and STAT3 in gastric cancer. Mol Cancer 2010, 9:269.

33. Yoo JY, Wang W, Desiderio S, Nathans D: Synergistic activity of STAT3 and c-Jun at a specific array of DNA elements in the alpha 2-macroglobulin promoter. J Biol Chem 2001, 276:26421-26429.

34. Lee S, Shen R, Cho HH, Kwon RJ, Seo SY, Lee JW, Lee SK: STAT3 promotes motor neuron differentiation by collaborating with motor neuronspecific LIM complex. Proc Natl Acad Sci U S A 2013, 110:11445-11450. 
35. Lenz G, Wright GW, Emre NC, Kohlhammer H, Dave SS, Davis RE, Carty S, Lam LT, Shaffer AL, Xiao W, Powell J, Rosenwald A, Ott G, Muller-Hermelink HK, Gascoyne RD, Connors JM, Campo E, Jaffe ES, Delabie J, Smeland EB, Rimsza LM, Fisher RI, Weisenburger DD, Chan WC, Staudt LM: Molecular subtypes of diffuse large B-cell lymphoma arise by distinct genetic pathways. Proc Natl Acad Sci U S A 2008, 105:13520-13525.

36. Dai B, Zhao XF, Hagner P, Shapiro P, Mazan-Mamczarz K, Zhao S, Natkunam Y, Gartenhaus RB: Extracellular signal-regulated kinase positively regulates the oncogenic activity of MCT-1 in diffuse large B-cell lymphoma. Cancer Res 2009, 69:7835-7843.

37. Chao MP, Alizadeh AA, Tang C, Myklebust JH, Varghese B, Gill S, Jan M, Cha AC, Chan CK, Tan BT, Park CY, Zhao F, Kohrt HE, Malumbres R, Briones J, Gascoyne RD, Lossos IS, Levy R, Weissman IL, Majeti R: Anti-CD47 antibody synergizes with rituximab to promote phagocytosis and eradicate non-Hodgkin lymphoma. Cell 2010, 142:699-713.

38. Elenitoba-Johnson KS, Jenson SD, Abbott RT, Palais RA, Bohling SD, Lin Z, Tripp S, Shami PJ, Wang LY, Coupland RW, Buckstein R, Perez-Ordonez B, Perkins SL, Dube ID, Lim MS: Involvement of multiple signaling pathways in follicular lymphoma transformation: p38-mitogen-activated protein kinase as a target for therapy. Proc Natl Acad Sci U S A 2003, 100:7259-7264.

39. Takata K, Miyata-Takata T, Sato Y, Yoshino T: Pathology of follicular lymphoma. J Clin Exp Hematop 2014, 54:3-9.

40. Vita M, Henriksson M: The Myc oncoprotein as a therapeutic target for human cancer. Semin Cancer Biol 2006, 16:318-330.

41. Slack GW, Gascoyne RD: MYC and aggressive B-cell lymphomas. Adv Anat Pathol 2011, 18:219-228

42. Ott G, Rosenwald A, Campo E: Understanding MYC-driven aggressive B-cell lymphomas: pathogenesis and classification. Hematology Am Soc Hematol Educ Program 2013, 2013:575-583.

43. Peters SL, Hlady RA, Opavska J, Klinkebiel D, Novakova S, Smith LM, Lewis RE, Karpf AR, Simpson MA, Wu L, Opavsky R: Essential role for Dnmt1 in the prevention and maintenance of MYC-induced T-cell lymphomas. Mol Cell Biol 2013, 33:4321-4333.

44. Zamo A, Chiarle R, Piva R, Howes J, Fan Y, Chilosi M, Levy DE, Inghirami G: Anaplastic lymphoma kinase (ALK) activates Stat3 and protects hematopoietic cells from cell death. Oncogene 2002, 21:1038-1047.

45. Aoki Y, Feldman GM, Tosato G: Inhibition of STAT3 signaling induces apoptosis and decreases survivin expression in primary effusion lymphoma. Blood 2003, 101:1535-1542.

46. Wu ZL, Song YQ, Shi YF, Zhu J: High nuclear expression of STAT3 is associated with unfavorable prognosis in diffuse large B-cell lymphoma. J Hematol Oncol 2011, 4:31.

47. Manni S, Brancalion A, Mandato E, Quotti Tubi L, Tubi LQ, Colpo A, Pizzi M, Cappellesso R, Zaffino F, Di Maggio SA, Cabrelle A, Marino F, Zambello R, Trentin L, Adami F, Gurrieri C, Semenzato G, Piazza F: Protein kinase CK2 inhibition down modulates the NF-kappaB and STAT3 survival pathways enhances the cellular proteotoxic stress and synergistically boosts the cytotoxic effect of Bortezomib on multiple Myeloma and mantle cell lymphoma cells. PLoS One 2013, 8:e75280.

48. Barre B, Vigneron A, Coqueret O: The STAT3 transcription factor is a target for the Myc and riboblastoma proteins on the Cdc25A promoter. J Biol Chem 2005, 280:15673-15681.

49. Liu Z, Li T, Liu Y, Jia Z, Li Y, Zhang C, Chen P, Ma K, Affara N, Zhou C: WNT signaling promotes $\mathrm{Nk} \times 2.5$ expression and early cardiomyogenesis via downregulation of Hdac1. Biochim Biophys Acta 2009, 1793:300-311.

50. Zhang Y, Zhang H, Liang J, Yu W, Shang Y: SIP, a novel ankyrin repeat containing protein, sequesters steroid receptor coactivators in the cytoplasm. EMBO J 2007, 26:2645-2657.

doi:10.1186/1476-4598-13-181

Cite this article as: Zhang et al: ISL-1 is overexpressed in non-Hodgkin lymphoma and promotes lymphoma cell proliferation by forming a p-STAT3/p-c-Jun/ISL-1 complex. Molecular Cancer 2014 13:181.

\section{Submit your next manuscript to BioMed Central and take full advantage of:}

- Convenient online submission

- Thorough peer review

- No space constraints or color figure charges

- Immediate publication on acceptance

- Inclusion in PubMed, CAS, Scopus and Google Scholar

- Research which is freely available for redistribution

Submit your manuscript at www.biomedcentral.com/submit
C Biomed Central 